emerald
PUBLISHING

Kybernetes

A knowledge structures exploration on social network sites

\begin{tabular}{|r|l|}
\hline Journal: & Kybernetes \\
\hline Manuscript ID & K-01-2016-0013.R2 \\
\hline Manuscript Type: & Research Paper \\
\hline Keywords: & $\begin{array}{l}\text { Perceived Community Support, Relationship Quality, Technology } \\
\text { Acceptance Model, Social Network Sites, Pathfinder Network Scaling }\end{array}$ \\
\hline \multicolumn{2}{|l}{} \\
\hline
\end{tabular}

SCHOLARONE ${ }^{m}$

Manuscripts 


\section{A knowledge structures exploration on social network sites}

Key Words: Perceived Community Support, Relationship Quality, Technology Acceptance Model, Enjoyment, Anxiety, Self-Efficacy, Pathfinder Network Scaling.

JEL Classification: M15, M39. 


\section{Introduction and study purpose}

As the growth and usage level of Social Network Sites (hereinafter, SNS) become a global phenomenon and organisations claim the relevance of enduring social bonds with respect to individuals' decision-making processes (Arenas-Gaitan et al., 2013; Wang \& Chang, 2013), the focus of marketing research shifts from enticing individuals to adopt SNS to ensuring high-value relationships with others. "In the last few years, social media has become an important source of knowledge and enables the creation of the content value chain" (Roblek et al., 2013, p.558). In this vein, the intangible cues of online social services imply the development of a true relationship-based approach and, consequently, growing calls for research which helps us to understand how users' true-loyalty is formed in SNS.

Our study firstly designs a research proposal to aid in exploring perceived community support (hereinafter, PCS) based on (1) the development of benefits derived from the preferential treatment and cooperation between individuals and groups, and (2) high levels of relationship quality (hereinafter, RQ) reflected in satisfaction and trust (e.g., Crosby et al., 1990; Hennig-Thurau \& Klee, 1997; Hennig-Thurau et al., 2002). On the one hand, PCS is made up of feelings of being supported by others in the online community, active interactions with it (and its membership groups), and stronger bonds to close members. The exchange of mutual support, integration and fulfilment of needs are essential motives for the long-lasting existence of SNS (Wellman \& Guilia, 1999). Individuals employ online social services because they are connected in a person-to-person manner which is more direct and interpersonal, perceive the possibility of obtaining resources based on utility and enjoyment from them, and expect to gratify social-emotional needs (Rau et al., 2008). On the other hand, the success of SNS is also based on RQ that is considered as a foremost marketing concept to predict the enhancing of electronic loyalty, and defined as "the degree of appropriateness of a relationship to fulfill the needs of the customer associated with that relationship" (Hennig-Thurau \& Klee, 1997, p.751). The present study extends previous research on SNS by using a marketing framework - the RQ model (e.g. Crosby et al., 1990; Dwyer et al., 1987, among others) - focusing on the true commitment phase of the behaviour chain model (cf. Fogg \& Eckles, 2007).

Secondly, over the years scholars have become increasingly aware of the relevance of the non-cognitive aspects (e.g., how enjoyable the SNS would be) in understanding attitudes towards use of services (e.g., Bagozzi et al., 1999). A main purpose of this study is thus to reveal how the intrinsic drivers are associated with a true relationship-based approach. On the one hand, hedonic motivation is conceptualised as the pleasure the individual feels objectively when committing a particular behaviour or carrying out a particular activity (Moon and Kim, 2001). When this occurs, an individual derives intrinsic enjoyment from the usage of the system and tends to continue with it (Igbaria et al., 1996). On the other hand, in order to experience intrinsic enjoyment while engaged in online social interactions, members must perceive a balance between their competences and the challenges of the activity. Challenges must be above a critical threshold, and selfefficacy is assumed as a belief of one's capability to use the SNS (cf. Wood \& Bandura, 1989). Otherwise, users may become anxious (cf. computer anxiety as discomfort or fear when using the SNS or when thinking about using the SNS).

In this situation of development, a proposal based on Technology Acceptance Model (hereinafter, TAM; cf. Davis, 1989; Davis et al., 1992) and flow (essentially defined as an intrinsically enjoyable experience; Sánchez-Franco \& Roldán, 2005), is designed to describe the main motives that, first, affect SNS acceptance and usage and second, make using the SNS a compelling customer-experience. Flow is a positive, highly-enjoyable state of consciousness that occurs when our perceived skills match the perceived challenges we are undertaking. When this occurs, an individual derives intrinsic enjoyment from the activity and tends to continue with it.

Thirdly, assuming that the study of hedonic-motivation systems such as SNS is still at the initial stage, our research also proposes that the success of an SNS is associated partially with its functionality and utility (e.g., seeking information). In this sense, the utilitarian nature of SNS is still unclear (Ernst et al., 2013). As Constantinides et al. (2013) note, there is not much research about the use of TAM to explain the acceptance of social technologies (cf. also Shin 2008). TAM is a prominent theoretical model in the field of information systems, "but it has received much less attention and appreciation in communication research" (Wang et al., 2012). TAM based on the Theory of Reasoned Action (Fishbein and Ajzen, 1975) and the Theory of Planned Behaviour (Ajzen, 1991; Ajzen \& Fishbein, 1980) is here utilised to explain which drivers are essential to foster community participation in an SNS. TAM has, as the theory most employed in adoption and acceptance research (Venkatesh \& Bala, 2008), proven to be a useful theoretical model in helping to understand and explain use behaviour in IS domain, and it has proven to be parsimonious and robust (Pavlou, 2003; Sánchez-Franco, 2006).

Fourthly, research shows that individual differences influence true relationship-based approaches. Differences arising from personal traits are highly relevant for validly predicting behavioural choices of services because this variation is at the heart of the customer decision-making process (Holbrook \& Hirschman, 1982; Roehrich, 2002). Although the study of online social environments became an early focal 
point for researchers, "they know little about characteristics of individual users who spark communication or influence its content" (Huffaker, 2010, p.593). Our research in particular examines the interacting role of accumulation of knowledge (e.g., beliefs and opinions) derived from service encounters (e.g., Gefen, 2000; Lee \& Kwon, 2011; Ng, 2013). Following Casaló et al. (2008), the intensity of the interrelations of our research proposal could change over time; i.e., loyalty antecedents might vary according to the members' experience. Therefore, as the benefits of SNS might be evaluated differently by new and long-term members, our research suggests examining the relational approach by levels of user familiarity. Integrating familiarity - described as "an understanding based on previous interactions, experiences, and learning of what, why, where and when others do what they do" (Gefen, 2000, p. 727) - brings about a richer understanding of knowledge structures located in the memory of young users of SNS. Familiarity (as a dynamic, situation-specific individual difference) is indeed considered to be one of the main drivers of individuals' behaviour, and it is here defined as "an individual's knowledge regarding other community members and their activities within the community" (Shen et al., 2010, p. 52). To sum up, our research examines the moderating role of accumulation of knowledge derived from service encounters during previous successful interactions (e.g. Gefen 2000; Lee \& Kwon 2011; Ng 2013, among others). Given that customer familiarity is a significant precondition for validly predicting behavioural choices of technologies and services, community managers could effectively enhance customers' PCS by targeting their underlying familiarity.

Finally, the complexity of individuals' knowledge structures based on levels of familiarity is measured using a Pathfinder network algorithm. The Pathfinder technique is very effective and efficient for the display of complex relationships between objects such as sophisticated networks, and it is well established in the cognitive psychology literature (Fesel, 2015). Our study precisely investigates beliefs-structures of familiarised and non-familiarised users - focusing on how users organise concepts and attributes in memory. As a user becomes more knowledgeable in a domain, he/she begins to organise his/her beliefs about PCS, $\mathrm{RQ}$ and extended TAM by constructing meaningful relationships between beliefs and opinions rather than merely accumulating declarative knowledge.

Next, our study describes the research method that is adopted to analyse the research proposal. The results and analysis follow the research design. This paper also outlines the limitations and implications for future research.

\section{Research questions and Method}

The present study is designed to examine knowledge structures located in the memory of young users of SNS. In particular, our present research demonstrates a method of combining opinions and beliefs about $\mathrm{PCS}, \mathrm{RQ}$ and extended TAM into one network representation in the context of SNS, and also analyses individual differences based on user familiarity.

In doing so, it attempts to address the following research questions: What form do the network representations between PCS, RQ and TAM take in online social environments? In particular, would the associations between the above dimensions be more direct amongst highly familiarised individuals? When users log in to an SNS, they exhibit somewhat less logical behaviour as they are probably exploring the system. The initial behaviour is quite different from more familiarised behaviours and may manifest itself in different representations.

\subsection{Participants}

In Spain, 79 per cent of Internet users (under age 55) have a profile on an SNS. Among young adults, this percent is higher. Research carried out with young undergraduate students concluded that $91.2 \%$ participate in SNS (cf. Gómez et al., 2012). 53\% connect several times a day and basically agree that the usage of SNS is one of their daily tasks.

Our participants are recruited during the autumn semester 2014 by requests distributed in a variety of social sites (i.e., Facebook, WhatsApp, Linkedin, etc). The survey period is 4 weeks. Individuals are asked to indicate the SNS that they use. The results show that $85 \%$ young respondents use Facebook (i.e., 289 individuals). Facebook, as the most popular SNS (1.2 billion people around the world). Our research thus chooses Facebook as the SNS for the present study. These are $54 \%$ male and $46 \%$ female. The age range is from 18 to 34 years.

There are several specific advantages to surveying homogeneous samples. On the one hand, the research reduces the moderating influences of third-constructs. Representative sampling of subjects is not necessary when conducting theoretical user research. Sampling a barely homogeneous group of subjects also inflates the error in statistical tests and reduces the likelihood of detecting systematic violations of a theory when it is false. In this vein, our research considers a homogeneous sample to ensure increasing the internal validity of our findings (Calder et al., 1981). On the other hand, young people are relevant users of SNS in comparison to the general population. They use it to communicate with their peers (e.g., Boneva et al., 2006). Emerging adulthood is defined as "a state of exploration and instability" (Arnett, 2004, p. 21) which defines their identity and intimacy through connections with friends and family members (Subrahmanyam et 
al., 2008). Descriptive and ethnographic research on the behaviour of young people in Internet highlights that SNS are essential for the development of personal identity, mediate in the relationships of young people with their friends, partners and broad groups (e.g., Agosto \& Abbas, 2010; Ito et al., 2009), boost trust and loyalty (Radmacher \& Azmitia, 2006), and foster the obtaining of social support (Larose et al., 2001). SNS promote social interaction and its reciprocity to attain purposes of communication, enjoyment and socialisation (Leung \& Lee, 2012; Osorio et al., 2014).

Our research performs a rigorous data pre-processing to handle anomalies, insincere data, and missing values. We firstly exclude questionnaires with missing values or inaccurate values for relevant items (i.e., 26 questionnaires). We remove the foreign individuals from the dataset (which was less than $1 \%$ of the total dataset) because of possible influences due to national-cultural scripts. Secondly, K-means clustering allows segmenting the data based on members' familiarity in such a way that the within-cluster variation is minimised. The effective sample is analysed using NbClust (cf. R programming language) to identify the number of potential clusters in the data. Nine indexes propose two clusters as the best number of clusters (cf. Charrad et al., 2014, for a review of used indexes). We also remove possible outliers via K-means clustering (i.e., 6 outliers). We get a total number of 253 usable responses. The function Clusplot (cf. R programming language) is used to identify the effectiveness of segmenting.

In Table 1 the high relative group is recognised with higher familiarity (152 individuals), whereas the low relative attitude group was identified with a lower level of familiarity (101 individuals). The study is conducted using $\mathrm{R}$ programming language and software environment for statistical computing.

Tab. 1: K-means clustering. Descriptive statistics.

\begin{tabular}{cccc}
\hline Cluster: High & $\mathrm{n}$ & mean & sd \\
\hline FAM1 & 152 & 6.090 & 0.770 \\
FAM 2 & 152 & 5.760 & 0.840 \\
FAM 3 & 152 & 5.330 & 0.940 \\
\hline Cluster: Low & & & 1.200 \\
\hline FAM 1 & 101 & 4.340 & 1.130 \\
FAM 2 & 101 & 3.930 & 1.040 \\
\hline FAM 3 & 101 & 2.780 & \\
\hline
\end{tabular}

\subsection{Measures}

A self-administered questionnaire is used to collect explicit beliefs and opinions about extended $P C S, R Q$ and extended TAM, user familiarity, and socio-demographic data. Instrument development consists in reviewing the literature so as to identify measures for each construct (Appendix 1). A pre-test assesses the suitability of the wording and format, and the extent to which measures represent all facets of the constructs. In particular, the questionnaire is pretested with four e-business professors. They assess the suitability of the wording and format and the extent to which measures represented all the facets of the constructs. Suggestions are incorporated into a second version that is then tested by two other e-business professors. No additional suggestions are made. All items use seven-point Likert-type scales ranging from 1, "strongly disagree", to 7 , "strongly agree".

On the one hand, to investigate the moderating effects, our research conducts sample segmentation based on sex and age (18 to 24 , and 25 to 34 years old). It compares the means of the same construct between groups by sex and age by independent-sample t-tests. Overall, the results indicate no significant differences between the groups; thus we pool the data from these groups together. On the other hand, we conduct a confirmatory factor analysis (CFA) to test the validity of the constructs, including item loading, construct reliability, and average variance extracted (AVE). The study is conducted using $R$ language. CFA provides evidence of an acceptable model fit. Composite reliability for all factors in our measurement model was above 0.7. The AVEs are all above the recommended 0.5 level. Following Hair et al.'s (1992) recommendations factor loadings greater than 0.5 are considered significant. The items in the research model have factor loadings greater than 0.5, excepting TRUST7 and PEOU5. Both are eliminated. The construct validity is acceptable. To examine discriminant validity, our research compares the shared variances between factors with the AVE of the individual factors. The shared variance between factors is lower than the AVE of the individual factors, excepting between community participation and community integration -i.e., social integration or 'sense of virtual community' defined here as the "members' feelings of membership, identity, belonging, and attachment to a group that interacts primarily through electronic communication" (see Blanchard, 2007, p. 827). community participation and community integration are thus considered as a unidimensional construct named social integration representing both the sense of belongingness to and the identification with the SNS -e.g., feeling like my online community is my own- and the social community's interactivity level -e.g., participating in order to stimulate my online community - as an effective route to well-being. See Table 2. 
Tab. 2: AVE, and discriminant validity

\begin{tabular}{l|cccccccccc}
\hline & FAM & C.ORG & S.INT & TRUST & SAT & PU & PEOU & ANX & ENJ & SE \\
\hline FAM & $\mathbf{0 . 7 2 8}$ & & & & & & & & & \\
C.ORG & 0.354 & $\mathbf{0 . 7 7 9}$ & & & & & & & \\
S.INT & 0.596 & 0.759 & $\mathbf{0 . 7 1 9}$ & & & & & & \\
TRUST & 0.217 & 0.505 & 0.450 & $\mathbf{0 . 7 2 8}$ & & & & & & \\
SAT & 0.538 & 0.536 & 0.654 & 0.552 & $\mathbf{0 . 7 0 1}$ & & & & & \\
PU & 0.569 & 0.610 & 0.701 & 0.389 & 0.676 & $\mathbf{0 . 7 4 4}$ & & & & \\
PEOU & 0.363 & 0.182 & 0.305 & 0.153 & 0.267 & 0.392 & $\mathbf{0 . 7 4 5}$ & & & \\
ANX & -0.318 & -0.002 & -0.183 & -0.106 & -0.240 & -0.202 & -0.096 & $\mathbf{0 . 6 9 6}$ & & \\
ENJ & 0.511 & 0.480 & 0.611 & 0.250 & 0.545 & 0.614 & 0.289 & -0.309 & $\mathbf{0 . 7 9 5}$ & \\
SE & 0.452 & 0.038 & 0.188 & 0.047 & 0.264 & 0.453 & 0.464 & -0.117 & 0.266 & $\mathbf{0 . 9 1 0}$ \\
\hline
\end{tabular}

Diagonal elements (bold) are the square root of the variance shared between the constructs and their measures (AVE). Off-diagonal elements are the correlations among constructs. For discriminant validity, diagonal elements should be larger than off-diagonal elements.

Note: FAM: familiarity; C.ORG: community organisation; S.INT: social integration; TRUST: trust; SAT: satisfaction; PU: perceived usefulness; PEOU: perceived ease of use; ANX: anxiety; ENJ: enjoyment; SE: self-efficacy.

\subsection{Procedure: Pathfinder network scaling}

The Pathfinder network scaling developed by Schvaneveldt et al. (1985a) is a valid approach for deriving network structures from relatedness data. Pathfinder's output is a directionless network, not causal, and the proposed model is not necessarily assumed to reflect unobserved, underlying concepts. The literature also suggests that Pathfinder network scaling reflects the structure of conceptual domains better than multidimensional scaling. The Pathfinder network scaling shows local relations among concepts (local structures), "which are psychologically meaningful and possesses higher predictive power of free recall performance compared with other multidimensional scaling (MDS) representations" (Lau \& Yuen, 2009, p.233). MDS's lack of explicit links makes it difficult to interpret the semantic dimensions. The non-directed least-path networks Pathfinder produces allow for analysis and observation of interesting relationships between concepts in a particular domain (Kreie et al., 2005). Pathfinder does not force a hierarchical structure on the data but identifies meaningful links between concepts (Jonassen et al., 1993).

The Pathfinder network scaling involves the conversion of a set of relatedness judgments into psychological proximities, resulting in a fully connected, weighted network of concepts and relationships. A key assumption is the triangle inequality condition; only those links that satisfy this condition appear in the final network (Chen \& Paul, 2001; Schvaneveldt, 1990). Pathfinder network is a form of structural assessment that measures the non-hierarchical interrelationships between the concepts comprising an individual's knowledge structure. It works by selecting the pairs with the shortest distance (i.e., greatest similarity) between them (either directly or through a path) while maintaining complete interconnectivity among all the nodes. Network structures therefore depict more complex interrelationships between the concepts comprising the individual's knowledge structure.

Similarity measures for item pairs are derived by calculating the cosine measure between the ratings vectors for each item with each other items which are previously typified. Our similarity matrix is here symmetric, being the distance irrespective of the direction of the relationship between pairs of items. Following partly Branaghan and Hildebrand (2011), the resulting matrix is submitted to a Pathfinder algorithm (Interlink, 2009) using the parameters of $q=n-1$ ( $n$ is the number of nodes in a network) and $r=\infty$. On the one hand, the r-parameter is the Minkowski metric used to compute the distance of a path. On the other hand, the q-parameter (here, 45) specifies the maximum length of a path subject to the triangle inequality test. The q parameter is indeed chosen in order to generate the sparsest network possible from the given data. The model proposed is conducted using Knowledge Network Organising Tool (KNOT).

\section{Results and discussion}

A large number of similarity judgments are obtained from our participants and used to generate a representation of their structures based on beliefs and opinions, assumed to represent the assessments that individuals have about the various concepts analysed. Structures are based on the premise that individuals organise their beliefs into patterns that reflect relationships between them and the features that define them. In this sense, two Pathfinder networks, one for the most familiarity and one for the less familiarised users, are generated. Pathfinder allows here for the direct comparison of the representations, and such a comparison makes it possible to determine the effectiveness of strategies based on true relationships in online social settings.

The Pathfinder algorithm supplies two networks of comparable complexity. KNOT provides graphical representations of networks presented in Figure 1. This layout may be used to qualitatively evaluate the results. Both networks have been graphically enhanced by Adobe Illustrator CS6. The number of links is 
equal to 52 (familiarised users) and 47 (non-familiarised users). The similarities between pairs of nodes in one network are compared to the similarities between the same pairs of concepts in another network, which provides a measure of the similarity of data sets (cf. Goldsmith \& Davenport, 1990). The correlation of the data in all the pairs of data files is here equal to 0.845 . Our analysis also includes the coherence of each data set (0.847, non-familiarised users' data set, and 0.912, familiarised users' data set). Coherence values reflect the consistency of the data. A low coherence value (less than 0.20) indicates that rates did not (or could not) take the rating task seriously (or technical difficulties). In particular, the coherence scores for nonfamiliarised users are lower than those of the more advanced users. Since the knowledge structures of experts are more organised than those of novices, experts in a given domain should possess relatively higher coherence scores (Goldsmith \& Kraiger, 1996).

The similarity between both networks (Goldsmith \& Davenport 1990) is determined by the correspondence of bonds in the two networks, i.e., the number of bonds in common divided by the total number of unique bonds in the two networks. This examines the degree to which a concept in the networks analysed is surrounded by similar neighbouring concepts. For our research, this procedure assesses the degree to which the non-familiarised users' elicited structure, defined by the proximity data, approximates the familiarised users' structure. Two identical networks yield a similarity of one (for identical networks -concepts are similarly connected in both networks), and two networks that share no links yield a similarity of zero (for complementary networks) (Lim \& Klein, 2006). In this sense, our research compares the number of links two networks have in common (23 links), the number of links in common less the number expected by chance (20.634), the similarity measure (0.303), the similarity corrected for chance $(0.278)$, and the probability of obtaining at least the number of common links observed by chance (0.000). The results therefore find a slight similarity between both networks. Although individuals are subjected to the same 46 nodes for judgments and it is expected that there would be commonality between the networks since they all deal with users' behaviour in SNS, our research shows that members differ in the way they represent and bundle their networks related to PCS, RQ and TAM.

In particular, familiarity about the functioning of an SNS is here defined as the number of SNS-related direct or indirect experiences with the SNS that has been accumulated by members (cf. Rothaermel \& Sugiyama 2001), and the familiarised users would therefore emphasise the perceived usefulness, intrinsic enjoyment and community participation. In this vein, the three concepts show minimum eccentricities (see Figure 1, left side). An SNS should thus be designed to be stimulating to use and to evoke compelling user experiences, and enhance the degree to which familiarised users believe that using the SNS helps them to attain gains in task performance.

Familiarised users (in an intrinsic enjoyment state) focus their attention on a limited stimulus field, filtering out irrelevant thoughts and perceptions. Users are less concerned with the risks associated with tasks, and are likely to feel motivated to act in an innovative and efficient way. In particular, familiarity would affect users' information processing activities in several ways, leading to a representation based on efficiency-based service encounters and intrinsic enjoyment - defined as the extent to which participation in an SNS is perceived to be pleasurable, exciting, enjoyable, and fun (Ghani \& Deshpandé, 1994; Sánchez-Franco, 2006). First, as users use a service more frequently, they are more familiar with it, reducing uncertainty in future decision situations, and enhancing relationships with others by elaborating advanced knowledge structures (Bhattaherjee, 2001; Flavián et al., 2006a; Gefen, 2000). Second, familiarised users believe that they know an SNS well, showing an individual judgment of one's capability to use an SNS and more positive and enjoyable beliefs and assessments about it. Once users attain a level of perceived ability and control with the SNS, they are free to explore its capabilities. That is to say, situations in which challenges and skills are perceived to be similar are assumed to facilitate intrinsically enjoyable experiences. Third, Zajonc and Markus (1982) propose that familiarity leads to positive assessments of a service. Familiarity required for the successful execution of SNS causes a positive reception to the idea of social interactions conducted online.

In sum, highly familiarised individuals are likely to be less concerned with the usability (i.e., perceived ease of use) of SNS, being located in lower centred positions. Likewise, Our research evidences a direct link between active participation and community organisation stressing the performance expectancy of such interactions with the needs of the community organisation (e.g., responding to calls to support my community - as an effective route to wellbeing). Moreover, perceived usefulness is weighed strongly and directly linked to intrinsic enjoyment. Although higher perceived control should lead to greater experiential behaviour through enjoyment emotional responses, our research shows how individuals do not fully evidence the direct interrelatedness (i.e., between intrinsic enjoyment and self-efficacy) in the domain of online social services. 
Fig. 1: Visualisation of Pathfinder network scaling. Higher familiarity vs lower familiarity
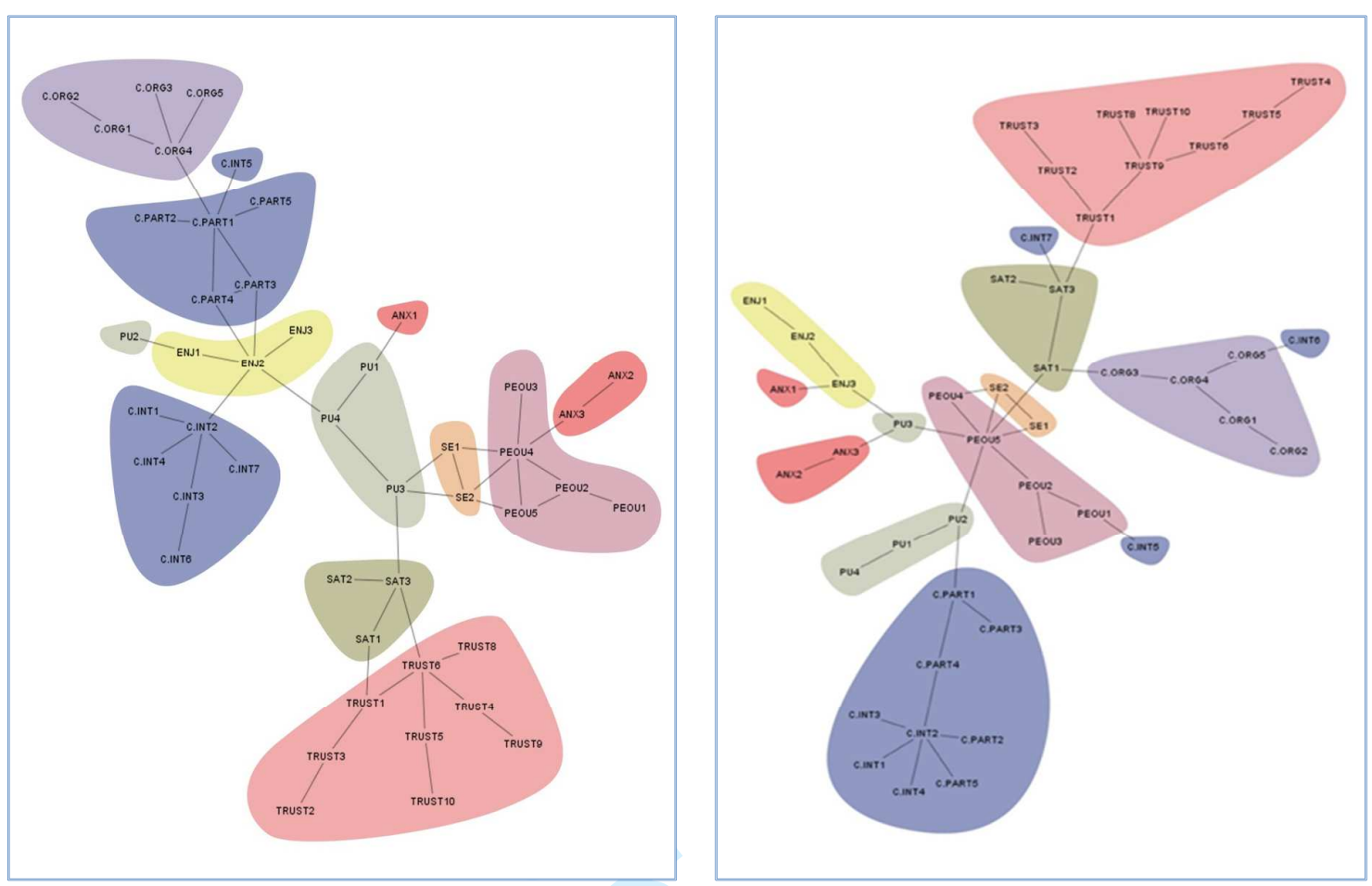

Note: FAM: familiarity; C.ORG: community organisation; C.INT: community integration; C.PART: community participation; TRUST: trust; SAT: satisfaction; PU: perceived usefulness; PEOU: perceived ease of use; ANX: anxiety; ENJ: enjoyment; SE: self-efficacy.

Meanwhile, non-familiarised users emphasise items related to perceived ease of use, community organisation and satisfaction. See Figure 1 (right side). The key term related to perceived ease of use is an essential node in this network as a representation of individuals' mental models. Non-familiarised users describe their structures in terms of the degree to which a person believes that using a SNS would be free of effort (cf. Davis 1989) and as a source of support, with online exchange of support being as helpful as support provided by offline contacts (Turner et al., 2001). The lower self-efficacy of perceptions among nonfamiliarised users can cause an increase in the salience of the effort of expectancy in determining behavioural intention towards SNS. Lower self-evaluations might emphasise the consideration of more cues related to the degree to which a user believes that using an SNS is free of effort. Whereas familiarised users primarily expect an SNS to be mainly useful and enjoyable, and may disregard issues arising from service complexity, non-familiarised users primarily emphasise the perceived ease of use and a feeling of being assisted by the online community in terms of support needs and resources available to the user (community organisation; $c f$. Herrero and Gracia, 2007). The high perceived risk associated with SNS usage significantly reduces non-familiarised users' perception of the belief in one's effectiveness in performing target tasks (cf. here application-specific self-efficacy, cf. Agarwal et al., 2000) and, in turn, ease of use. These users may not be willing to accept a complex interface. Community managers should then design a supportive mechanism and an affable environment (e.g., enhancing online interaction and communication among members, or periodic face-to-face meetings) that more effectively foster the individuals' self-efficacy.

Following Schvaneveldt et al. (1985b, p.700; cf. also Meyer \& Schavaneveldt, 1976), "two concepts that are directly linked are viewed as more similar than are two concepts that are not linked or are indirectly linked". Highly-related concepts consequently end up directly connected, and less-related concepts require the traversal of two or more links. On the one hand, familiarised users find the cumulative online social interactions rewarding, fulfilling and stimulating. Interactions involve introspective social experiences and integration -which refers to concrete involvement in activities. Familiarity results in a (partial) cognitive link between participation and community integration via intrinsic enjoyment. Following the previous literature about user familiarity would thus present social integration as a second-order construct formed by community participation and community integration which exists on the same level as the dimensions, and is inherently associated with intrinsic enjoyment. Both dimensions of the social integration construct would be themselves constructs conceived as specific components of the general construct they collectively constitute. On the other hand, non-familiarised members would not be aware of conceptual differences between the two community dimensions, social integration existing as a superordinate second-order construct reflected in community participation and community integration -based on the inter-correlations between first-order factors forming a system of interdependence that is itself important in measuring the high-order integration. 
Social integration would be a general concept that is manifested by its dimensions. In this sense, SánchezFranco et al. (2015) also propose a positive covariance between community participation and community integration defined as "members' feelings of membership, identity, belongingness, and attachment to a group that interacts primarily through electronic communication" (Blanchard, 2007, p. 827; cf. also Blanchard, 2008; McMillan \& Chavis, 1986).

Furthermore, the importance of privacy in determining online trust should be even greater for categories with personal information at risk - for example, online social services - than it is for other online categories (Bart et al. 2005). Trust determines the extent to which users engage in a relationship. The perceived risk of a relationship is high due to the lack of face-to-face contact (Ridings et al. 2002) when community members are still unfamiliar with one another. Non-familiarised users should thus tend to demonstrate a greater concern with the risk of online services and SNS anxiety. Contrariwise, when familiarised customers evaluate an SNS through fulfilling, gratifying interactions, the need to trust - by developing PCS - becomes less relevant (cf. Sánchez-Franco 2009); people may become more willing to accept uncertainty and vulnerability as they are able to draw from direct experience, rather than surface cues, to inform their expectations regarding the future behaviour of an SNS. To sum up, non-familiarised users are slower in becoming loyal users and spend longer deciding to try new services. An expert user of the SNS is more likely to have a greater confidence in the SNS than a novice user. Although trust constructs and maintains the exchange of ideas in an interconnection (Blau, 1964) when familiarised/expert individuals evaluate an SNS through fulfilling, and easy interactions the need to trust disappears. However, anxiety and trust are clearly located in the periphery of both knowledge networks. The level of average eccentricity of trust and anxiety is also high in the non-familiarised sample. SNS customers overestimate their uncertainties perceptions, underestimate their trust between the parties, and could damage the creation of PCS and relational capital which exists when individuals have a strong identification and trust in a network (Wasko \& Faraj, 2000). A possible explanation could lie in users' desire for users' popularity. Although lower levels of familiarity in SNS and trust in other members should be a significant predictor of higher levels of information control and lower information disclosure on SNS (Walrave et al., 2012), members may easily prioritise their desire for popularity at the expense of their privacy (Sánchez-Franco et al., 2015). According to Christofides et al. (2009, p.342), "despite privacy concerns, individuals disclose a great deal of personal information". Assuming these associative networks, SNS must therefore promote friend groupings, item-level access control, block lists and back a range of other techniques for privacy management.

\section{Conclusion}

Overall, our research focuses on the association between PCS, RQ and utilitarian- and hedonic-benefits among young adults. On the one hand, it assesses the perceptions of young adults who are currently using SNSs, focusing on the true commitment phase of the behaviour chain model, and thus assuming that the ultimate success of SNSs derives from a long-lasting usage. On the other hand, it proposes that greater levels of motivations based on receiving comfort, empathy, and other relationship benefits lead young adults to feel that they are being supported by a whole portion of their social community, and stressing a sense of emotional involvement with others. In this vein, social capital increases members' feelings of attachment to their SNS and expectations of continuity, so that young adults strengthen relationships with others and obtain affective benefits from mutual relationships (cf. Casaló et al., 2007). The amount and depth of support that members receive from other members are here positively associated with community participation, a lower uncertainty of their relationship quality with it, and an enhancement of community integration. Likewise, perceived enjoyment and extrinsic antecedents based on TAM (i.e., perceived ease of use, and perceived usefulness) are overall identified as important motivational factors in SNS acceptance and usage. Finally, our research proposes the need for focusing on different individual characteristics.

In particular, to guarantee the community's survival in the long term, community managers should encourage young adults to share knowledge and ideas related to mutual interest, to develop stronger feelings of being supported by the SNS and to strengthen their identity, belonging, and attachment to it by stimulating (a) the degree to which a member believes that the information obtained from the SNS will provide a range of relational benefits that would otherwise be difficult to obtain without participating in it, (b) the pleasure the individual feels objectively when practising a particular behaviour or carrying out a particular activity, (c) extrinsic motivation that describes an individual's personal gain associated with the use of a particular SNS, and the degree to which a member believes that using the online social service would be free of effort to evaluate the virtual community positively. Moreover, our study recommends the analysing of isolated subsets of individuals' characteristics and subsequent behaviours related to PCS, RQ or extended TAM based on utilitarian- and hedonic-motives. For instance, assuming here that familiarity is a significant cue for validly explaining choices of SNSs, community managers might enhance members' loyalty by targeting their levels of interactions, experiences, and learning of what, why, where and when others do what they do (Gefen, 2000). Our research empirically analyses a theory-grounded framework for integrating individual characteristics and relational drivers, and it focuses on associative structures evidenced as a representation of the most salient loyalty-based concepts by modelling the interactive effects of familiarity. 
Accordingly, a Pathfinder network scaling algorithm is applied to analyse patterns in proximity data in a model which represents them spatially in a network-based graph. Pathfinder networks provide not only a fuller representation of the salient knowledge structures than minimal spanning trees, "but also a more accurate representation of local structures than multidimensional scaling techniques" (Chen, 2006). This study therefore contributes to the analysis of enduring social bonds with respect to individuals' decisionmaking processes as it provides details representing specific relationships between diverse concepts based on true-loyalty. The application of Pathfinder to the study of online social services and user behaviour appears to have the potential for unveiling the structures (based on opinions and beliefs) of SNS members and designing successful strategies for prospective community managers.

\section{Implications and future research}

Community managers should attempt to extend their relational models by examining more antecedents and understanding more dimensions and quasi moderators that drive users' continuance interaction and active participation. Community managers should search for reliable ways to foster their young members' continuance interaction. Firstly, half of all new members abandon their SNSs soon after the creation of their accounts ( $\mathrm{Li}, 2011)$. It is relevant for community managers to understand the cues that drive the social interaction at a deeper level. In this regard, young people with a higher personal innovativeness may dive into the technology due to their curiosity and not necessarily base their social integration on the support needs and resources available to them. Young people with a higher personal innovativeness might engage in a social behaviour that increases participation and integration without adjusting fully to the community supports one receives from one's relationships with other members. A lower personal innovativeness trait appeared to rely more on feelings of being assisted by the community to intensify affective commitment, that is to say, on the perceived usefulness of the SNS in terms of experiences founded on being loved and cared for by the other members. Future research should thus focus on individual-level antecedents of social integration.

Secondly, future research does not rely on a marketing viewpoint alone (e.g., RQ) but also on developing community tools employing drivers of Human-Computer Interactions (e.g., online design). On the one hand, community managers need first of all to ensure that an SNS is technically sound, with good security practices put in place to minimise the risks for the initial users. On the other hand, visual design, related to hedonic motivations, is becoming one of the most important factors that influences users' affective experiences and their emotional bonds in online social environments (Hassenzahl \& Tractinsky, 2006; Kim et al., 2009; Tractinsky et al., 2000; Wolfinbarger \& Gilly, 2003). Expressive issues become essential drivers that provide engagement (i.e., affective commitment) in the use of SNSs. Young adults seek enjoyable fulfilment and deep optimal stimulation as part of the usage experience. If young users find virtual appearances pleasing, it is likely that both their state of mind and subsequent implied evaluations will be favourably enhanced.

Likewise, TAM-based models have successfully guided many studies in Information Technology, and its adoption, acceptance, routinisation and infusion. For instance, perceived ease of use, or usability, is a significant key among less familiarised young-adults. SNS should thus simplify the design of their appearance and layout to enhance usability, i.e., easier access to information typically increases noneconomic satisfaction. In this vein, an appreciation of only hedonic benefits weakens the understanding of the drivers of customer acceptance. "Information and communication technology that is difficult to learn and difficult to use will induce negative emotions (...) and thus generate avoidance behaviour toward technology use" (Zhang 2007). In this regard, for non-familiarised young people who learn a 'new technology', the adoption decision is more likely to be promoted by its perceived ease of use in comparison to familiarised members.

Thirdly, SNSs may result in undesirable consequences (e.g., social rejection, loneliness, cyberbullying and diminished personal identity, among others; cf. Walrave et al., 2012). Lower levels of familiarity in SNS and trust in other members should be antecedents of lower information disclosure on SNS. However, young members may easily prioritise their desire for popularity, and be apathetic to privacy online (cf. Figure 1). Accordingly, Park (2011; cf. also Litt, 2013, p.1651) comments that "one's technical familiarity and online experience, in terms of years of usage and daily Internet use, impacted individuals' privacy strategies". Indeed, despite privacy concerns, young adults disclose a great deal of personal information, and are less aware of the risks of sharing personal information and are at risk of harassment by cyberbullies (cf. Kornblum, 2007).

SNSs should therefore allocate efforts to trust-based initiatives that should assist the progressive reduction of technological anxiety via environmental security, operational competence, and operational benevolence (Johnson, 2007). It is essential to young adults to be aware and knowledgeable about how their shared personal information is used by other members. SNSs should first attempt to emphasise trust in the goodwill of the management in its users' affairs, showing a determined willingness to understand and comprehend their needs and to be a company capable of promoting social integration. It is essential for SNS to give priority to users' interests and to be reliable - that is to say, order fulfilment and absence of errors. SNS should thus prioritise their support for the control perceived by non-familiarised young users by making 
available clear rules and management procedures, as well as the required legal aspects and seals of approval, as indicators of security, that will reduce levels of uncertainty in their relationship with community members. To sum up, "measures should be implemented to raise young Internet users' awareness of the consequences of using personal information inappropriately or making it accessible to too many people online" (Casas, Del Rey, and Ortega-Ruiz 2013,585) by educating members about their personal data with a privacy policy and by providing privacy controls. Stutzman, Capra, and Thompson $(2011,597)$ suggest that "users need understandable privacy policies and usable privacy controls".

\section{Limitations}

A key limitation of this study is the use of non-probability sampling. The selection of the respondents might have been subject to a sample selection bias and, therefore, possible refinements in this direction are advisable for future research. Since the young adults' perception and intention can change over time, it is also relevant to measure these quantities at several points of time. Likewise, our research does not cover the full scale of possible options. For instance, it is difficult to generalise this model and extend the results to other social settings. Our study is indeed conducted using data from a field survey of Facebook. This therefore, limits the external validity of our findings.

Moreover, the specific cultural context, gender and age may have affected our findings. For instance, future research ought to analyse whether the development of feelings of being supported by others in an SNS, and an active participation in it are affected by gender, assuming previous evidence (in terms of social orientation and behavioural motivation) which indicates that females are more oriented toward interpersonal relationships, and have lower perceptions of self-efficacy. In this regard, there are indications that biological gender differences in computer anxiety and computer performance are not found in cultures characterised by non-masculinisation of the computer. These therefore, need to be interpreted with care.

To sum up, when future researchers attempt to apply our findings, our study recommends a repetition of this research using a wider sample of individual characteristics and cultures, and other social settings.

\section{Acknowledgments}

This research was supported by the Andalusian Government, Spain -Research Project of Excellence SEJ-5801. 


\section{References}

Agarwal, R., Sambamurthy, V., \& Stair, R.M. (2000). Research report: The evolving relationship between general and specific computer self-efficacy-an empirical assessment. Information Systems Research 11, 418-430.

Agosto, D., \& Abbas, J. (2010). High school seniors' social network and other ICT use preferences and concerns. Proceedings of the American Society for Information Science and Technology, 47(1), 1-10.

Ajzen, I. (1991).The theory of planned behaviour. Organizational Behavior and Human Decision Processes, $50(2), 179-211$.

Ajzen, I., \& Fishbein, M. (1980). Understanding attitudes and predicting social behaviour. Englewood Cliffs, New Jersey: Prentice-Hall.

Arenas-Gaitan J., Rondan-Cataluña, F. J., \& Ramírez-Correa, P. (2013). Social identity, electronic word-ofmouth and referrals in social network services. Kybernetes, 42(8), 1149-1165.

Arnett, J. J. (2004). Emerging adulthood: The winding road from the late teens through the twenties. New York, EUA: Oxford University Press.

Bagozzi, R.P., Gopinath, M., \& Nyer, P.U. (1999). The role of emotions in marketing. Journal of Academy of Marketing Sciences, 27(2), 184-206.

Bart, I., Shankar, V., Sultan, F., \& Urban, G.L. (2005). Are the drivers and role of online trust the same for all web sites and customers? A large-scale exploratory empirical study. Journal of Marketing, 69(4), 133-52.

Bhattacherjee, A., \& Premkumar, G. (2004). Understanding changes in belief and attitude toward information technology usage: A theoretical model and longitudinal test. MIS Quarterly, 28(2), 229-54

Blanchard, A.L. (2007). Developing a sense of virtual community measure. CyberPsychology \& Behaviour, 10(6), 827-830.

Blanchard, A.L. (2008). Testing a model of sense of virtual community. Computers in Human Behaviour, 24(5), 2107-2123.

Blau, P. M. (1964). Exchange and Power in Social Life. New York: Wiley and Sons.

Boneva, B. S., Quinn, A., Kraut, R. E., Kiesler, S., \& Shklovski, I. (2006). Teenage communication in the instant messaging era. In R. Kraut, M. Brynin, \& S. Kiesler (Eds.). Information technology at home (pp. 612672). New York: Oxford University Press.

Bonsón Ponte, E., Carvajal-Trujillo, E., \& Escobar-Rodríguez, T. (2015). Corporate Facebook and stakeholder engagement. Kybernetes, 44(5), 771-787.

Branaghan, R.J., \& Hildebrand, E.A. (2011). Brand personality, self-congruity, and preference: A knowledge structures approach. Journal of Consumer Behaviour, 10, 304-312.

Calder, B. J., Lynn, W. P., \& Tybout, A. M. (1981). Designing research for application. Journal of Consumer Research, 8(2), 197-207.

Casaló, L., Flavian, C., \& Guinaliu, M. (2007). The impact of participation in virtual brand communities on consumer trust and loyalty: the case of free software. Online Information Review, 31(6), 775-792.

Casaló, L., Flavián, C., \& Guinalíu, M. (2008). Promoting consumer's participation in virtual brand communities: A new paradigm in branding strategy. Journal of Marketing Communications, 14(1), 19-36.

Casas, J.A., Del Rey, R., \& Ortega-Ruiz, R. (2013). Bullying and cyberbullying: Convergent and divergent predictor variables, Computers in Human Behavior, 29(3), 580-587.

Charrad M, Ghazzali N, Boiteau V, \& Niknafs, A. (2014). A NbClust: An R Package for Determining the Relevant Number of Clusters in a Data Set. Journal of Statistical Software 61(6), 1-36.

Chen, Ch. (2006). Information Visualization: Beyond the Horizon, 2nd edition. London: Springer-Verlag. Chen, Ch., \& Paul, R.J., 2001. Visualizing a knowledge domain's intellectual structure. Computer, 34(3), 6571.

Christofides E., Muise A., \& Desmarais S. (2009). Information Disclosure and Control on Facebook: are They Two Sides of the Same Coin or Two Different Processes? CyberPsychology \& Behavior, 12(3), 341-5.

Constantinides, E., Lorenzo-Romero, C. and Alarcón-del-Amo, M.C. (2013). Social networking sites as business tools: A study of user behavior. Studies in Computational Intelligence, 444, 221-240.

Crosby, L.A., Evans, K.R., \& Cowles, D. (1990). Relationship quality in services selling: An interpersonal influence perspective. Journal of Marketing, 54(3), 68-81.

Davis, F.D. (1989). Perceived usefulness, perceived ease of use and user acceptance of information. MIS Quarterly, 13, 319-342.

Davis, F.D., Bagozzi, R.P., \& Warsaw, P.R. (1992). Extrinsic and intrinsic motivation to use computers in the workplace. Journal of Applied Social Psychology, 22, 1111-1132.

Dick, A., Jain, A., \& Richardson, P. (1995). Correlates of store brand proneness: some empirical observations. Journal of Product and Brand Management, 4(4), 15-22.

Dwyer, R. F., Schurr, P. H., \& Oh, S. (1987). Developing buyer-seller relationship. Journal of Marketing, 51 (April), 11-27.

Ernst, C.P.H., Pfeiffer, J., \& Rothlauf, F. (2013). Hedonic and Utilitarian Motivations of Social Network Site Adoption. Working Paper, 01, 1-14.

Fesel, S.S. (2015). Children's digital text comprehension. MA thesis, Behavioural Science Institute, Radboud University, Nijmegen, The Netherlands. 
Fishbein, M., \& Ajzen, I. (1975). Belief, Attitude, intention, and behavior: An introduction to theory and research. Reading, MA: Addison-Wesley.

Flavián, C., Guinalíu, M., \& Gurrea, R. (2006a). The influence of familiarity and usability on loyalty to online journalistic services: The role of user experience. Journal of Retail and Consumer Services, 13, 363-375.

Flavián, C., Guinalíu, M., \& Gurrea, R. (2006b). The role played by perceived usability, satisfaction and consumer trust on website loyalty. Information and Management, 43(1), 1-14.

Fogg, B. J., \& Eckles, D. (2007). The Behavior Chain for Online Participation: How Successful Web Services Structure Persuasion. In Y. DeKort, W. Ijsselstein, C.J.H. Midden, B. Eggen, B.J. Fogg (Eds.), PERSUASIVE (pp. 199-209). Springer, LNCS 4744.

Gefen, D. (2000). E-Commerce: The role of familiarity and trust. Omega: The International Journal of Management Science, 28(6), 725-737.

Geyskens, I., Steenkamp, J.-B, Scheer, L.K., \& Kumar N. (1996). The effects of trust and interdependence on relationship commitment: A trans-atlantic study. International Journal of Research in Marketing 13(4), 303317.

Ghani, J.A., \& Deshpande, S.P. (1994). Task characteristics and the experience of optimal flow in humancomputer interaction. The Journal of Psychology, 128(4), 383-91.

Goldsmith, T., \& Kraiger, K. (1996). Applications of structural knowledge assessment to training evaluation. In J.K. Ford, S. Kozlowski, K. Kraiger, E. Salas, \& M. Teachout (Eds.). Improving training effectiveness in work organizations (pp.73-97). Mahwah, NJ: Lawrence Erlbaum.

Goldsmith, T.E., \& Davenport, D.M. (1990). Assessing structural similarity of graphs. In R. W. Schvaneveldt (Ed.), Pathfinder associative networks: Studies in knowledge organization (pp.75-87). Norwood, NJ: Ablex. Gómez, M., Roses, S., \& Farias, P. (2012). The Academic Use of Social Networks among University Students. Comunicar, 38(29), 131-138.

Gursoy, D. (2001). Development of a travelers' information search behavior model. Thesis Dissertation, Faculty of the Virginia Polytechnic Institute and State University.

Hair, J.T., Anderson, R.E., Tatham, R.L., \& Black, W.C. (1992). Multivariate Data Analysis with Readings, third ed. New York: Macmillan.

Harrison, A.W., \& Rainer, R.K., Jr. (1992). An examination of the factor structures and concurrent validities for the computer attitude scale, the computer anxiety rating scale, and the computer self-efficacy scale. Educational and Psychological Measurement, 52, 735-742.

Hassenzahl, M., \& Tractinsky, N. (2006). User experience: A research agenda. Behaviour and Information Technology, 25, 91-97.

Hennig-Thurau, T., \& Klee, A. (1997). The impact of customer satisfaction and relationship quality on customer retention: A critical reassessment and model development. Psychology and Marketing, 14(8), 73764.

Henning-Thurau, T., Gwinner, K.P., \& Gremler, D.D. (2002). Understanding relationship marketing outcomes - An integration of relational benefits and relationship quality. Journal of Service Research, 4(3), $230-247$. Herrero, J., \& Gracia, E. (2007). Measuring perceived community support: Factorial structure, longitudinal invariance, and predictive validity of the PCSQ (Perceived Community Support Questionnaire). Journal of Community Psychology, 35(2), 197-217

Holbrook, M.B., \& Hirschman, E.C. (1982). The Experiential Aspects of Consumption: Consumer Fantasies, Feelings, and Fun. Journal of Consumer Research, 9 (September), 132-140.

Huffaker, D. (2010). Dimensions of leadership and social influence in online communities. Human Communitcation Research, 36(4), 593-617.

Igbaria, M., Parasuraman, S., \& Baroudi, J.J. (1996). A motivational model of microcomputer usage. Journal of Management Information Systems, 13 (1), 127-143.

Ito, M., Baumer, S., Bittanti, M., Boyd, D., Cody, R., \& Herr-Stephenson, B. (2009). Hanging out, messing around, and geeking out: Kids living and learning with new media. Cambridge, MA, EUA: MIT Press.

Janda, S., Trocchia, P.J., \& Gwinner, K.P. (2002). Consumer perceptions of Internet retail service quality. International Journal of Service Industry Management, 13(5), 412-431.

Jonassen, D. H., Beissner, K., \& Yacci, M. (1993). Structural knowledge: Techniques for representing, conveying, and acquiring structural knowledge. Hillsdale, NJ: Lawrence Erlbaum Associates.

Kim, J.H., Kim, M., \& Kandampully, J. (2009). Buying environment characteristics in the context of e-service. European Journal of Marketing, 43(9/10), 1188-1204

Kornblum, J. (2007, October 22). Online privacy? For young people, that's oldschool. USA Today. Retrieved March 20, 2009, from http://www.usatoday.com/tech/webguide/internetlife/2007-10-22-online-privacy_N.htm Kreie, J., Alt., K., Cronan, T.P., \& Leonard, L.N.K. (2005). Do Ethical Views Differ In Different Situations? Using Pathfinder Associative Networks to Compare Views. Proceedings of the 2005 Information Systems Educators Conference, 1-8.

LaRose, R., Eastin, M. S., \& Gregg, J. (2001). Reformulating the internet paradox: Social cognitive explanations of internet use and depression. Journal of Online Behavior, 1(2). 
Lau, W. \& Yuen, A. (2009). Predictive validity of measures of the pathfinder scaling algorithm on programming performance: Alternative assessment strategy for programming education. Journal of Educational Computing Research, 41 (2), 227-25

Lee, Y., \& Kwon, O. (2011). Intimacy, familiarity and continuance intention: an extended expectationconfirmation model in web-based services. Electronic Commerce Research and Applications, 10(3), 1034210357.

Leung, L., \& Lee, P. S. N. (2012). The influences of information literacy, internet addiction and parenting styles on internet risks. New Media \& Society, 14(1), 117-136.

Li, D.C. (2011). Online social network acceptance: a social perspective. Internet Research, 21(5), 562-580.

Lim, B.C., \& Klein, K.J. (2006). Team mental models and team performance: A field study of the effects of team mental model similarity and accuracy. Journal of Organizational Behaviour, 27, 403-418

Litt, E. (2013), Understanding social network site users' privacy tool use, Computers in Human Behavior, 29(4), 1649-1656.

Loewenfeld, F. (2006). Brand communities - Erfolgsfaktoren und Ökonomische Relevanz von Markeneigenschaften. Deutscher, Wiesbaden, Universitäts-Verlag.

Lorenzo, C., Alarcón, M.C., \& Gómez, M.A. (2011). Adopción de redes sociales virtuales: Ampliación del modelo de aceptación tecnológica integrando confianza y riesgo percibido. Cuadernos de Economía y Dirección de la Empresa, 14(3), 194-205.

Lowry, P.B., Gaskin, J., Twyman, N., Hammer, B., \& Roberts, T.L. (2013). Proposing the hedonic- motivation system adoption model (HMSAM) to increase understanding of adoption of hedonically motivated systems. Journal of the Association for Information Systems, 14(11), 617-671.

McKnight, D. H., Kacmar, C. J., \& Choudhury, V. (2004). Dispositional trust and distrust distinctions in predicting high- and low-risk internet expert advice site perceptions. e-Service Journal, 3(2), 35-58.

McMillan, D. W., \& Chavis, D. M. (1986). Sense of community: A definition and theory. Journal of Community Psychology, 14(1), 6-23.

Meyer, D. E., \& Schvaneveldt, R. W. (1971). Facilitation in recognizing pairs of words: Evidence of a dependence between retrieval operations. Journal of Experimental Psychology: General, 90, 227-234.

Moon, J., \& KIM, Y. (2001). Extending the TAM for a World-Wide-Web context. Information and Management, $38,217-230$.

$\mathrm{Ng}$, C.S. (2013), Intention to purchase on social commerce websites across cultures: A cross-regional study. Information \& Management, 50(8), 609-620.

Osorio, M. J., Molero, M. M., Pérez, M. C., \& Mercader, I. (2014). Redes sociales en internet y consecuencias de su uso en estudiantes universitarios. International Journal of Developmental and Educational Psychology INFAD Revista de Psicología, 3(1), 585-592.

Park, Y.J. (2011). Digital literacy and privacy behavior online. Communication Research, 40(2), 215-236.

Pavlou, P.A. (2003). Consumer Acceptance of Electronic Commerce: Integrating Trust and Risk with the Technology Acceptance Model. Journal International Journal of Electronic Commerce, 7 (3) 101-134.

Radmacher, K., \& Azmitia, M. (2006). Are there gendered pathways to intimacy in early adolescents' and emerging adults' friendships? Journal of Adolescent Research, 21(4), 415-448.

Ridings, C., Gefen, D., \& Arinze, B. (2002). Some antecedents and effects of trust in virtual communities. Journal of Strategic Information Systems, 11(3-4), 271-295.

Roblek, V., Pejic Bach, M., Meško, M., \& Bertoncelj, A. (2013). The impact of social media to value added in knowledge-based industries. Kybernetes, 42(4), 554-568.

Roehrich, G. (2002). Consumer innovativeness: Concepts and measurements. Journal of Business Research, 57, 671-677.

Rothaermel, F. T., \& Sugyama, S. (2001). Virtual internet communities and commercial success: Individual and community-level theory grounded in the atypical case of TimeZone.com. Journal of Management, 27(3), 297-312.

Saadé, R., \& Bahli, B., The impact of cognitive absorption on perceived usefulness and perceived ease of use in on-line learning: An extension of the technology assessment model. Information \& Management, 42, 317-327.

Sánchez Franco, M.J., \& Roldán, J.L. (2005). Web acceptance and usage model: a comparison between goal-directed and experiential web users. Internet Research-Electronic Networking Applications and Policy, 15, $21-48$.

Sánchez-Franco, M.J. (2006). Exploring the influence of gender on the web usage via Partial Least Squares. Behaviour and Information Technology, 25(1), 19-36.

Sánchez-Franco, M.J. (2009). The Moderating effects of involvement on the relationships between satisfaction, trust and commitment in e-banking. Journal of Interactive Marketing, 23(3), 247-258.

Sánchez-Franco, M.J., Buitrago-Esquinas, E., \& Yñiguez-Ovando, R. (2015). What drives social integration in the domain of social network sites? Examining the influences of relationship quality and stable and dynamic individual differences. Online Information Review, 39(1), 5-25.

Schvaneveldt, R. W. (1990). Pathfinder Associative Networks: Studies in Knowledge Organization. Norwood, $\mathrm{NJ}$ : Ablex Publishing Corp. 
Schvaneveldt, R. W., Durso, F. T., \& Dearholt, D. W. (1985a). Pathfinder: Scaling with network structures. Memorandum in Computer and Cognitive Science, MCCS-85-9, Computing Research Laboratory, New Mexico State University.

Schvaneveldt, R.W., Durso, F.T., Goldsmith, T.E., Breen, T.J., Cooke, N.M., Tucker, R.G., \& De Maio, J.C. (1985b). Measuring the structure of expertise. International Journal of Man-Machine Studies, 23(6), 699-728. Shen, Y.C., Huang, C.Y., Chu, C.H., \& Liao, H.C. (2010). Virtual community loyalty: an interpersonalinteraction perspective. International Journal of Electronic Commerce, 15(1), 49-73.

Shin, D.H. (2008). Understanding purchasing behaviors in a virtual economy: Consumer behavior involving virtual currency in Web 2.0 communities. Interacting with Computers, 20, 433-446.

Smith, J., \& Barclay, D. (1997). The e $\square$ ects of organizational di $\square$ erences and trust on the e $\square$ ectiveness of selling partner relationships. Journal of Marketing, 61, 3-21.

Subrahmanyama, K., Reichc, S. M., Waechterb, N., \& Espinozab, G. (2008). Online and offline social networks: Use of social networking sites by emerging adults. Social Networking on the Internet, 29(6), 420433.

Tractinsky, N., Katz, S.A., \& Ikar, D. (2000). What is beautiful is usable. Interacting with Computers, 13, 127145.

Turner, J. W., Grube, J. A., \& Meyers, J. (2001). Developing an optimal match within online communities: an exploration of CMC support communities and traditional support. Journal of Communication, 51(2), 231-251. Venkatesh, V., \& Bala, H. (2008). Technology acceptance model 3 and a research agenda on interventions. Decision Sciences, 39, 273-315.

Venkatesh, V., Morris, M.G., Davis, G.B., \& Davis, F.D. (2003). User acceptance of information technology: Toward a unified view. MIS Quarterly 27(3), 425-478

Walrave, M., Vanwesenbeeck, I., \& Heirman, W. (2012). Connecting and protecting? Comparing predictors of self-disclosure and privacy settings use between adolescents and adults. Cyberpsychology: Journal of Psychosocial Research on Cyberspace, 6(1).

Wang, H., Chung, J.E., Park, N., McLaughlin, M.L., \& Fulk, J. (2012). Understanding online community participation: A technology acceptance perspective. Communication Research, 39(6), 781-801

Wang, J. Ch., \& Chang, Ch.-H. (2013). How online social ties and product-related risks influence purchase intentions: A Facebook experiment. Electronic Commerce Research and Applications, 12(5), 337-346.

Wasko, M. M., \& Faraj, S. (2005). Why should I Share? Examining social capital and knowledge contribution in electronic networks of practice. MIS Quarterly, 29 (1), 35-57.

Wellman, B., \& Guilia, M. (1999). Net surfers don't ride alone: Virtual communities as communities. In B. Wellman (Ed.), Networks in the global village: Life in contemporary communities. Boulder, CO: Westview Press.

Wolfinbarger, M., \& Gilly, M.C. (2003). etailQ: Dimensionalizing, measuring and predicting etail quality. Journal of Retailing, 79(3), 183-198.

Wood, R., \& Bandura, A. (1989). Impact of conceptions of ability on self-regulatory mechanisms and complex decision making. Journal of Personality and Social Psychology, 56(3), 407-415.

Zajonc, R.B., \& Markus, H. (1982). Affective and cognitive factors in preferences. Journal of Consumer Research, 9, 123-31.

Zhang, P. (2007). Toward a positive design theory: principles for designing motivating Information and communication technology. In M. Avital, R. J. Boland and D.L. Cooperrider (eds.), Proceedings of the Positive Design Working Conference: Designing Information and Organizations with a Positive Lens, 2 , 2007, 1-363. 
Appendix 1: Measurement scales.

Constructs/Indicators

ENJ. Intrinsic Enjoyment (Saadé and Bhali, 2005; Lowry et al. 2013)

ENJ1. On the whole, interacting via the SNS is pleasurable

ENJ2. In general, I enjoy interacting via the SNS

ENJ3. Overall, interacting via the SNS arouses my curiosity

PU. Perceived Usefulness (Davis, 1989; Davis et al. 1992; Lorenzo-Romero et al. 2011; Sánchez-Franco, 2006)

PU1. I feel that the function and the utility of the SNS are useful for me

PU2. Using the SNS makes it easier to interact with other users

PU3. Using the SNS gives me access to a large quantity of information

PU4. In general, I find the SNS extremely useful

PEOU. Perceived Ease of Use (Davis, 1989; Davis et al. 1992; Lorenzo-Romero et al. 2011; Sánchez-Franco, 2006)

PEOU1. Learning to use the SNS is simple

PEOU 2. It's easy to learn how to use the SNS

PEOU 3. It's easy for me to do what I want to do on the SNS

PEOU 4. It's easy to remember how to use the SNS

PEOU 5. Interaction with the SNS is clear and understandable

PEOU 6. In general, I find the SNS easy to use

ANX. Anxiety (Harrison and Rainer, 1992)

ANX1.The SNS make me feel uneasy and confused

ANX2. Working with the SNS would make me very nervous

ANX3. I get a sinking feeling when I think of trying to use the SNS

SE. Self-Efficacy (Venkatesh et al. 2003; Sánchez-Franco and Rodríguez, 2004)

SE1. When I post new comments, information, experiences, photos, links, etc. I clearly know the right things to do

SE2. I feel confident posting new comments, information, experiences, photos, links, etc. if there is no one around to tell me what to do as I go

C.INT. Community Integration (Geyskens et al. 1996; Loewenfeld, 2006; Sánchez-Franco, 2009)

C.INT1. My emotional ties in the SNS I belong to are a key reason why I am still a member

C.INT 2. I feel at ease in the SNS; the relationships I have in the SNS are very enjoyable

C.INT 3. I feel a sense of ownership of the SNS; I feel like an integral part of it

C.INT 4. I identify myself with the SNS I belong to

C.INT 5. My opinions are generally valued by other members of the SNS where I am a member

C.INT 6. I feel emotional ties with the SNS I am a member of

C.INT 7. Interacting with and relating to other members means a lot to me

C.ORG. Community Organisation (Geyskens et al. 1996; Loewenfeld, 2006; Sánchez-Franco, 2009)

C.ORG1. I could find people that helped me feel better

C.ORG2. I could find someone to listen to me when I felt down

C.ORG 3. I could find a source of satisfaction for myself

C.ORG 4 . I could be able to cheer up and get into a better mood

C.ORG 5. I could relax and easily forget my problems

C.PART. Community Participation (Geyskens et al. 1996; Loewenfeld, 2006; Sánchez-Franco, 2009)

C.PART1. In general, I get actively involved in the SNS

C.PART 2. I am a member of different groups organised through the SNS, and I participate in these groups

C.PART 3. I contribute to the SNS by posting new comments, information, experiences, photos, links, etc.

C.PART 4. In general, I take notice of the comments and contributions of other members

C.PART 5. In general, I respond eagerly to comments made by other members on the SNS

TRUST. Trust (Lorenzo-Romero et al. 2010)

TRUST1. I feel that the SNS keeps the promises and commitments it makes

TRUST2. I believe that the information offered on the SNS is sincere and honest

TRUST3. Openness and transparency when providing services to users are characteristics of the SNS

TRUST4. The SNS is trustworthy

TRUST5. The SNS acts responsibly

TRUST6. In general, I trust the SNS

TRUST7. Posting personal information on the SNS doesn't really worry me

TRUST8. I believe that I can trust the SNS

TRUST9. I feel that the SNS's behaviour is ethical

TRUST10. I believe that the SNS is capable of performing its intended function

SAT. Satisfaction (Flavián et al. 2006b; Janda et al. 2002; Smith and Barclay, 1997)

SAT1.In general terms, I am satisfied with my experience in the SNS

SAT2.I think that I made the correct decision to use the SNS

SAT3.I have obtained several benefits derived from my participation in the SNS

FAM. Familiarity (Dick et al. 1995; Flavián et al. 2006a; Gursoy, 2001)

FAM1.Overall, I am quite familiar with the SNS

FAM2.I am very familiar with the services offered by the SNS

FAM3.In comparison with the typical user of the SNS, I believe I am quite familiar with it

SNS: Facebook. 